\title{
Conduction of sensory action potentials across the posterior fossa in infratentorial space-occupying lesions in man
}

\author{
AD WANG, L SYMON, F GENTILI \\ From the Gough Cooper Department of Neurological Surgery, Institute of Neurology, London
}

SUMMARY Central conduction time following median nerve stimulation has been recorded in 28 patients with infratentorial space occupying lesions. Fourteen of these $(50 \%)$ showed a prolonged central conduction time, which invariably involved that segment of the conduction time between the dorsal column nuclei generators and the generation site for P15, which we believe to be in the upper brain stem or thalamus. Three other cases showed prolongation of the N14-P15 segments though total central conduction time was within normal limits. One case with marked hydrocephalus showed prolongation both before and after the P15 wave. The possible pathophysiology of prolongation of central conduction time in these cases and the possible neural generation site of P15 are discussed.

Monitoring of short latency somatosensory evoked responses has been found of value in the study of acute cerebral ischaemia after subarachnoid haemorrhage, and associated intracranial aneurysm surgery. ${ }^{1}$ The measurement which has proved of greatest use has been that of central conduction time, the time of transit of the impulse recorded from a surface electrode at the second cervical spine, to a scalp electrode external to the somatosensory cortex, as described by Hume and Cant. ${ }^{2}$ Animal experimentation has confirmed that prolongation of the central conduction time may be related to the development of ischaemia. The central conduction time remained constant with cerebral blood flow above levels of around $15 \mathrm{ml} / 100 \mathrm{~g} / \mathrm{min}$, and increased significantly below this level of flow. ${ }^{3}$ Prolongation of conduction time has been shown to be prognostically related to the outcome of intracranial aneurysm surgery. ${ }^{4}$ This paper reports a study of somatosensory conduction in patients with posterior fossa lesions, and describes the altered transmission along the pathway.

\section{Material and methods}

Twenty-eight patients with infratentorial space occupying lesions were studied with bilateral recording of somatosensory evoked potentials following median nerve stimulation

Address for reprint requests: Professor L Symon, Institute of Neurology, Queen Square, London, WC1N 3BG, UK. (table 1). Square waves of $0.15 \mathrm{~ms}$ duration were delivered at a rate of $3 \mathrm{~Hz}$ to two silver cup electrodes $3 \mathrm{~cm}$ apart over the median nerve at the wrist. ${ }^{1}$ Stimulation intensity used was about 2-3 times subjective threshold, and sufficient to elicit a small thumb twitch. Recording electrodes were placed at the $\mathrm{C} 3 / \mathrm{C} 4$ position of the international 10-20 system, and over the midline of the back of the neck at C2 level. Frontal reference leads (Fpz) were used, and 1024 responses averaged from the contralateral scalp and C2 simultaneously using a Medelec MS6 system. Two averages from each arm were taken during a recording session. The impedance between the electrodes was checked at each recording session. Patients remained supine with eyes closed without sedation, but could be awake or asleep during the test. Central conduction time is defined as the time interval between the N14 peak recorded at $\mathrm{C} 2$ and the $\mathrm{N} 20$ peak recorded at cortex. Between these two major waves, a small positive deflection occurs which, according to previous classification has been called $\mathrm{P} 15^{56}$ and we have used the presence of this positive peak to divide central conduction time into two segments (N14-P15 and P15-N20). Although the exact origin of the $\mathbf{P} 15$ wave is still subject to debate, it is generally regarded as arising from the medial lemniscus or thalamus ${ }^{67}$ while the N14 wave is commonly regarded as taking its origin from the gracile and cuneate nuclei. The N20 wave probably signals the arrival of impulse at the cortex. Our own experimental work in the primate would indicate, from the disappearance of $\mathrm{N} 20$ during middle cerebral occlusion that the cortex is the most likely origin of $\mathrm{N} 20 .{ }^{15}$ We have studied changes in the proportion of the two segments of central conduction time in relation to posterior fossa tumours, and in eleven normal healthy volunteers who were tested as a control group. 
Table 1 Patients studied

\begin{tabular}{lclllll}
\hline Site of tumour & No of pts & $\begin{array}{l}\text { prolonged } \\
\text { central } \\
\text { conduction time }\end{array}$ & $\begin{array}{l}\text { prolonged } \\
\text { before P15 only }\end{array}$ & $\begin{array}{l}\text { prolonged after P15 only prolonged both sides } \\
\text { on }\end{array}$ & $\begin{array}{l}\text { central conduction time } \\
\text { within normal range }\end{array}$ \\
\hline Brain stem & 1 & 1 & 0 & 0 & 1 & 0 \\
4th ventricle & 3 & 3 & 2 & 0 & 1 & 0 \\
Cerebellar & 6 & 3 & 3 & 0 & 0 & $3(50 \%)$ \\
C-P angle & 14 & 7 & 7 & 0 & 0 & $7(50 \%)$ \\
Extending from middle fossa & 5 & 1 & 1 & 0 & 0 & $4(50 \%)$ \\
\hline
\end{tabular}

\section{Results}

DATE FROM NORMALS (table 2)

Central conduction time in normal subjects averaged $5.4 \pm 0.4 \mathrm{~ms}$, and in line with our previous work, values of greater than $6.4 \mathrm{~ms}$ (mean \pm 2.5 standard deviations), were regarded as abnormal. The interval N14-P15 in normal subjects averaged $27.8 \pm 4.2 \%$ of total conduction time, the range being $20.4-36.8 \%$. Intervals longer than $38.3 \%$ (mean $\pm 2.5 \mathrm{SD}$ ) were considered abnormal.

\section{DATA FROM PATIENTS}

Table 3 shows the data on the 28 patients. In the group as a whole, 14 of the 28 cases showed abnormally prolonged central conduction times. Twelve of these cases showed the prolongation only in the N14-P15 segment. There were two exceptions. A case of 4th ventricular ependymoma with a very prolonged central conduction time $(7.0 \mathrm{~ms})$ showed proportional prolongation of both the N14-P15 and the P15-N20 segment (fig 1). This patient had gross generalised hydrocephalus. The single brain stem tumour case had a prolonged central conduction time, the prolongation being mainly in the N14-P15 segment, although P15-N20 segment was also prolonged to a lesser extent (fig 2). All three 4th ventricular tumour cases had prolonged central conduction time, again mainly in the N14-P15 segment. In seven of the fourteen patients with cerebellopontine angle tumours who showed prolonged central conduction time, prolongation was once again in the N14-P15 portion. Three of the six cerebellar cases had prolonged central conduction time, all within the N14-P15 portion. Central conduction time was not prolonged in the three cases with inner third sphenoidal wing meningiomas involving the upper part of the posterior fossa. A central conduction time of $9.0 \mathrm{~m} / \mathrm{s}$ was recorded in a patient with a huge cholesteatoma extending from the middle fossa and grossly displacing the brain stem (fig. 3), and although another such case showed a normal central conduction time in both cases the N14-P15 interval was significantly prolonged.
Table 2 Components of central conduction time in normal subjects. (N14-N20)

\begin{tabular}{lc}
\hline N14 & $13.5 \pm 0.9 \mathrm{~ms}$ \\
P15 & $15.0 \pm 0.8 \mathrm{~ms}$ \\
N20 & $18.9 \pm 0.8 \mathrm{~ms}$ \\
N14-P15 & $1.5 \pm 0.3 \mathrm{~ms}$ \\
$\%$ of central conduction time & $27.8 \pm 4.2$ \\
P15-N20 & $3.9 \pm 0.3 \mathrm{~ms}$ \\
\% of central conduction time & $72.2 \pm 4.2$ \\
N14-N20 & $5.4 \pm 0.4 \mathrm{~ms}$ \\
\hline
\end{tabular}

Table 3 The portion of central conduction time represented by N14-P15 ("posterior fossa conduction")

\begin{tabular}{|c|c|c|c|c|c|c|}
\hline & \multicolumn{2}{|c|}{$\begin{array}{l}\text { I Patients with } \\
\text { prolonged central } \\
\text { conduction time } \\
\text { N14-P15 }\end{array}$} & \multicolumn{2}{|c|}{$\begin{array}{l}\text { II Patients without } \\
\text { prolonged central } \\
\text { conduction time } \\
\text { N14-P15 }\end{array}$} & \multicolumn{2}{|c|}{$\begin{array}{l}\text { III Normal subjects } \\
\text { N14-P15 }\end{array}$} \\
\hline & total (ms) & $\%$ & total (ms) & $\%$ & total $(\mathrm{ms})$ & $\%$ \\
\hline $\begin{array}{r}1 \\
2 \\
3 \\
4 \\
5 \\
6 \\
7 \\
8 \\
9 \\
10 \\
11 \\
12 \\
13 \\
14 \\
\\
\text { me } \\
7 \cdot \\
53 . \\
\text { (I) }\end{array}$ & $\begin{array}{c}16.6 \\
7 \cdot 0 \\
7 \cdot 2 \\
7.4 \\
6 \cdot 5 \\
6 \cdot 8 \\
7 \cdot 1 \\
6 \cdot 4 \\
7 \cdot 4 \\
6 \cdot 5 \\
8 \cdot 6 \\
6 \cdot 9 \\
6 \cdot 4 \\
9 \cdot 0 \\
(\mathrm{n}=14) \\
\pm \text { SD } \\
=2.6 \mathrm{~ms} \\
10.0 \\
\end{array}$ & $\begin{array}{l}60.2 \\
38.6 \\
54.2 \\
51.4 \\
52.3 \\
55.9 \\
70.4 \\
67.2 \\
40.5 \\
55.4 \\
54.7 \\
63.8 \\
40.6 \\
43.3\end{array}$ & $\begin{array}{l}5 \cdot 7 \\
5 \cdot 7 \\
6 \cdot 3 \\
5 \cdot 6 \\
6 \cdot 2 \\
5 \cdot 1 \\
5 \cdot 3 \\
5 \cdot 5 \\
5 \cdot 6 \\
5 \cdot 7 \\
5 \cdot 3 \\
5 \cdot 0 \\
5 \cdot 8 \\
4 \cdot 7 \\
(n=14) \\
\text { mean } \pm \text { S } \\
5 \cdot 5 \pm 0 . \\
35 \cdot 2 \pm 8 \cdot \\
(\text { II) }\end{array}$ & $\begin{array}{l}36 \cdot 8 \\
26 \cdot 3 \\
33 \cdot 3 \\
35 \cdot 7 \\
41 \cdot 2 \\
25 \cdot 5 \\
35 \cdot 8 \\
36 \cdot 4 \\
48 \cdot 2 \\
50 \cdot 9 \\
28 \cdot 3 \\
38 \cdot 0 \\
32 \cdot 8 \\
23 \cdot 4 \\
\\
4 \mathrm{~ms} \\
0\end{array}$ & $\begin{array}{l}5 \cdot 5 \\
5 \cdot 5 \\
6 \cdot 4 \\
5 \cdot 1 \\
5 \cdot 2 \\
5 \cdot 7 \\
5 \cdot 1 \\
5 \cdot 2 \\
5 \cdot 7 \\
5 \cdot 5 \\
4 \cdot 9 \\
(n=11)\end{array}$ & $\begin{array}{l}27 \cdot 3 \\
29 \cdot 1 \\
28 \cdot 1 \\
23 \cdot 5 \\
30.8 \\
36 \cdot 8 \\
29.4 \\
28 \cdot 8 \\
26 \cdot 3 \\
25 \cdot 5 \\
20.4\end{array}$ \\
\hline
\end{tabular}

Difference between I and II: $p=0.01$

Difference between II and III: $p=0.05$

Difference between I + II and III: $p=0.01$

(Mean + SD of I + II: $67 \pm 2 \cdot 2 / 44 \cdot 3 \pm 12 \cdot 9)$

Figure 4 shows histograms of the proportion of N14-P15 in relation to total central conduction time in normal patients and patients with posterior fossa tumour. Figure 5 shows the ratio of N14-P15 to total central conduction time in posterior fossa tumour cases with normal and prolonged central conduction time. This data is also shown in table 3. 


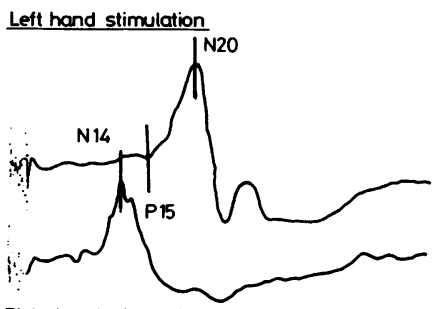

NK : $10.6 \mathrm{~ms}$

P15: $12.9 \mathrm{~ms}$

N20: $17.6 \mathrm{~ms}$

$\propto \mathrm{CT}: 7.0 \mathrm{~ms}$

N14-P15/CCT: $32 \cdot 9 \%$

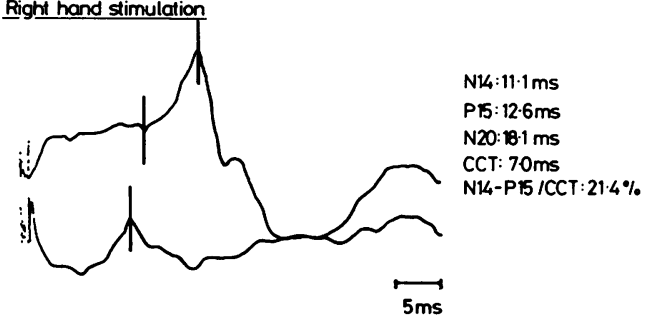

Fig 1 SSEP recorded from a 14-year-old patient with 4th ventricle ependymoma and marked hydrocephalus showing bilateral prolongation N14-P15 and P15-N20 segment.

Left hand stimulation

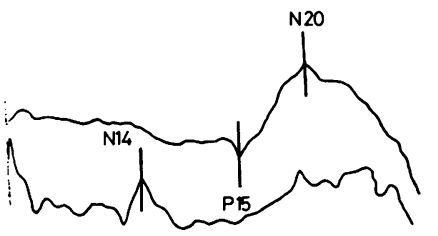

N14: $14.8 \mathrm{~ms}$

P15: $24.8 \mathrm{~ms}$

$\mathrm{N} 20: 31.4 \mathrm{~ms}$

CCT: $16.6 \mathrm{~ms}$

N14-P15/CCT: $60-2 \%$

Right hand stimulation

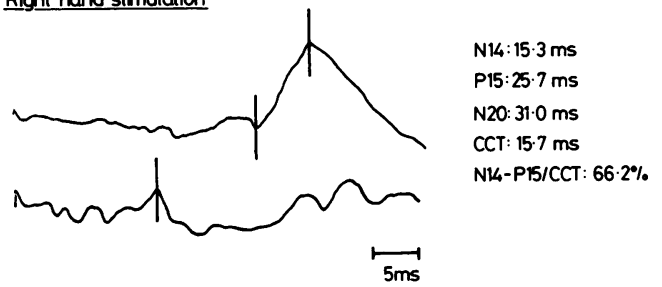

Fig. 2 SSEP recorded from a patient with an upper brain stem tumour showing bilateral very long conduction time, the prolongations mainly in the N14-P15 segment.

In patients with prolonged central conduction time (more than 6.4 ms), the actual range was 6.4-16.6 ms. In these cases, the N14-P15 segment varied between $38.6 \%$ and $70.4 \%$ of the total conduction time, (mean $53.5 \pm 10.0 \%$ ) the average central conduction time values being $7.8 \pm 2.6 \mathrm{~ms}$. The second group of patients with infratentorial spaceoccupying lesion, but without prolongation of the central conduction time, showed a range from 4.7$6.3 \mathrm{~ms}$ (mean $5.5 \pm 0.4 \mathrm{~ms}$ ). N14-P15 in these cases varied between 23.4 and $50.9 \%$, the average being $35 \cdot 2 \pm 8 \cdot 0 \%$.

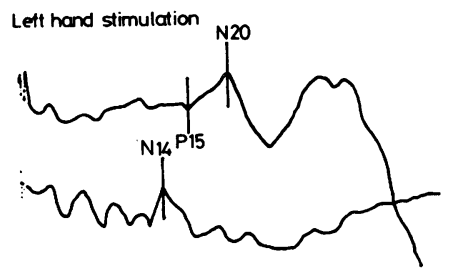

N14: $14 \cdot 8 \mathrm{~ms}$

P15: $17.6 \mathrm{~ms}$

$\mathrm{N} 20: 21.6 \mathrm{~ms}$

$\mathrm{CCT}: 6.8 \mathrm{~ms}$

N14-P15/CCT: $41 \cdot 2 \%$

Right hand stimulation

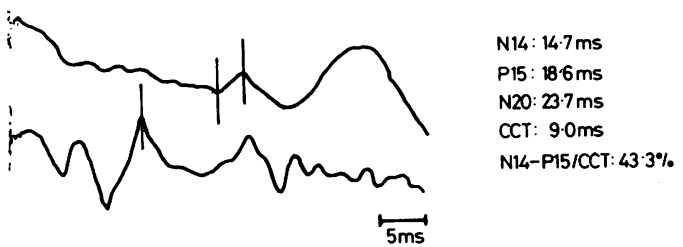

Fig 3 SSEP recorded from a 63-year-old patient with a cholesteatoma extending from the middle fossa to the posterior fossa encroaching on the brain stem, showing bilateral prolongation of central conduction time due to prolongation of the N14-P15 segment.

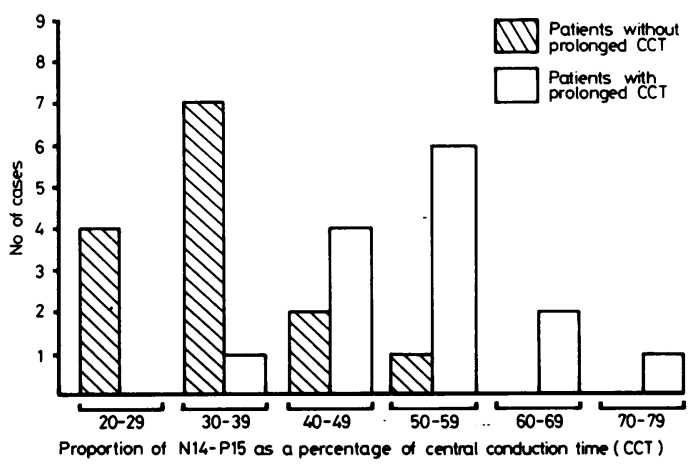

Fig 4 Histogram of the proportion of N14-P15 as a percentage of total central conduction time in patients and normal subjects.

Comparing the first group of cases, posterior fossa lesions with prolonged conduction time and normal subjects, the N14-P15 interval was significantly prolonged $(\mathrm{p}<0.01)$ (unpaired $t$ test). Even in those patients without significant prolongation of central conduction time compared with control, the interval N14-P15 was just significantly prolonged ( $p<$ $0.05)$. Combining the data of the posterior fossa cases with and without prolongation of central conduction time, the group as a whole were statistically different from normals $(p<0.01)$ in respect of the N14-P15 interval.

Central conduction time was bilaterally abnormal in the case with the brain stem tumour, and in three cases with tumour of the 4 th ventricle (fig. 6 ). Two 


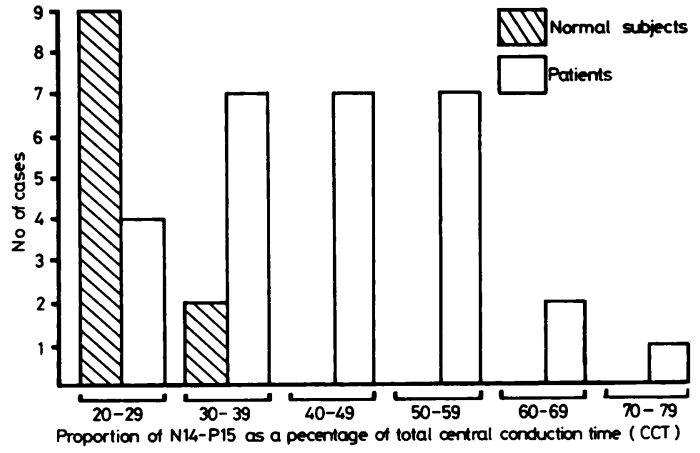

Fig 5 Histogram of the proportion of N14-P15 as a percentage of total central conduction time in patients with and without prolongation of total central conduction time.

Left hand stimulation

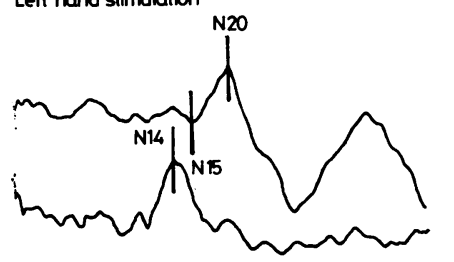

NK: $16.8 \mathrm{~ms}$ P 15: $19.4 \mathrm{~ms}$ N20: $23.2 \mathrm{~ms}$ CCT: $64 \mathrm{~ms}$ N14-PI5/CCT: $40 \cdot 6 \%$

Right hand stimulation

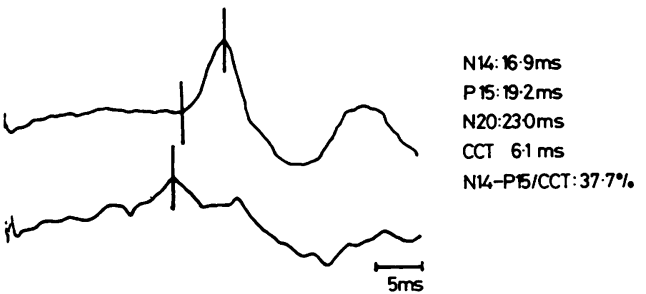

Fig 6 SSEP recorded from a patient with a right acoustic neuroma; left hand stimulation shows a prolonged central conduction time of 6.4 $\mathrm{ms}$ and the N14-P15 segment is $40.6 \%$ of total central conduction time.

of the three cerebellar cases with prolonged central conduction time showed bilateral prolongation. Among the seven cases of cerebellar pontine angle tumour with prolonged central conduction time, three showed bilateral changes while the four cases with unilaterally prolonged conduction, showed this abnormality on the side of the tumour and contralateral to stimulation.

\section{Discussion}

Since the demonstration of somatosensory evoked potentials on scalp recording following median nerve stimulation by Dawson in $1947,{ }^{8}$ there has been considerable interest in the analysis of evoked electrical activity at various levels in the neuraxis. The post-synaptic volley recorded over $\mathrm{C} 2$ at between 12 and $15 \mathrm{~ms}$ following median nerve stimulation, is now generally thought to represent the arrival of the afferent volley at the dorsal column nuclei, ${ }^{269-12}$ The origin of $\mathrm{N} 20$, the first major negative peak recorded from the scalp, has been thought by some authors to be cortical ${ }^{13}{ }^{14}$ although Chiappa in $1979^{12}$ believed rather in a subcortical origin for this peak. Experimental work in baboons ${ }^{15}$ has however indicated that the primary positive/negative wave of the somatosensory evoked response, either of trigeminal or of median nerve origin, is related to blood supply in the cerebral cortex: reduction in blood flow to levels below $16 \mathrm{ml} / 100 \mathrm{~g} / \mathrm{min}$ results in disappearance of this wave, and the technique of blood flow reduction, by middle cerebral occlusion in the baboon, ensures that the thalamic relays of the somatosensory pathway are outwith the area of ischaemia. The prompt change in the evoked response indicates that ischaemia in the white matter is unlikely to be responsible for the failure of the wave and our experimental work therefore leads us to believe that $\mathrm{N} 20$ is most likely synaptically based in the cortex. We have therefore considered the inter-peak latency between N14 and N20 as representing conduction time in the central nervous system as originally suggested by Hume and Cant.

The origin of P15 is less certain. It has been thought to take its origin either from transmission in the upper lemniscus, or possibly in the thalamus. ${ }^{56}$

As the amplitude of the somatosensory evoked response is dependent upon, among other things, electrode position, scalp thickness and stimulus intensity, we chose to measure only the latency of the components in our patients, which was less subject to changes in these parameters from day to day.

This present series documents prolongation of central conduction time in 14 of 28 patients with infratentorial space occupying lesions. The mechanism whereby such tumours induce prolongation of impulse conduction is not clear. A close relationship between impulse conduction and blood flow has been shown clinically in other circumstances. ${ }^{316}$ It is possible therefore that changes in patterns of perfusion within the brainstem resulting from the growth of a neoplasm, might affect conduction within the pathways. It is also possible, however, that a direct mechanical effect of compression on the pathways themselves could result in slowing of conduction. ${ }^{17}$ Although it is still too early to conclude whether mechanical pressure or change in regional blood flow is more likely to produce prolongation of nerve conduction in these cases, we can be sure that when mechanical pressure reaches a certain degree, regional tissue perfusion must also be altered. 
Further observation and experimentation is needed in this regard. In intrinsic tumours of the brain stem, distortion and destruction of neural pathways by the growth of the tumour itself might well explain the findings, but in this present series this mechanism could hardly be implicated except in one case.

This study has shown that all cases of prolonged central conduction time with a posterior fossa mass showed prolongation of that section of the sensory pathway between the dorsal column nuclei and the generation site of P15. A group of patients in whom the overall central conduction time was not prolonged with a posterior fossa lesion, nevertheless showed a prolonged N14-P15 segment suggesting involvement predominantly of the same section of the pathway. The preservation of P15 in these cases is of interest in contrast with its abolition seen in a number of tumours and intracerebral haematomas involving the thalamus itself (unpublished data). It seems to us therefore that the generation site of P15 could rationally be considered anatomically to be at or above the level of the tentorium. A likely origin of synaptic transmission to give rise to such a wave form, would be thalamus.

In the current series, the only case which showed proportional increase of central conduction time both before and after the P15 wave, was a fourth ventricular ependymoma with associated hydrocephalus. We consider that the fourth ventricular tumour itself would account for prolongation of the first portion of intracranial conduction between N14 and $\mathrm{P} 15$, as occurred in the other cases in the series. The explanation for prolongation of the second portion wave between P15 and N20 is probably the presence of the marked hydrocephalus. We have seen prolongation of the P15-N20 segment in other case of hydrocephalus and which has returned to normal with a CSF drainage procedure. Hydrocephalus was also present in one pontine tumour case which showed some prolongation in the P15N20 segment, though in this case the main lengthening of conduction was in the N14-P15 segment. A dilated ventricular system has been shown to be associated with delay in the conduction of visual evoked responses. ${ }^{18}$

The laterality of cerebello-pontine angle tumours enables study of change in conduction in a brain stem subjected predominantly to unilateral pressure. There were five large cerebello-pontine angle tumours in the present series which showed prolonged cental conduction time. In three of them, the prolongation was bilateral, presumably due to a generalised distortion of the brain stem as has been discussed. In the other two cases however, the change was unilateral, and the prolongation affected central conduction time to a median nerve stimulus contralateral to the side of the brain tumour (fig 6). This would suggest therefore that the main impact of an acoustic neuroma on the sensory conduction pathway occurs high in the angle. In all these cases, the size of the tumour was such that the tumour involved brain stem distortion from the level of the fifth nerve, downwards, that is above the level of the sensory decussation. A further study of tumours of graded size in this situation would confirm or refute this explanation, one might expect that delay in N14-P15 would occur first in relation to contralateral median nerve stimulation, and then bilaterally.

\section{References}

' Symon L, Hargadine J, Zawirski M, Branston NM. Central conduction time as an index of ischaemia in subarachnoid haemorrhage. J Neurol Sci 1979;44:95103.

${ }^{2}$ Hume AL, Cant BR. Conduction time in central somatosensory pathways in man. Electroencephalogr Clin Neurophysiol. 1978;45:361-75.

${ }^{3}$ Hargadine JR, Branston NM, Symon L. Central conduction time in primate brain ischaemia-a study in baboons. Stroke. 1980;11(6):637-42.

4 Symon L, Cone JD, Hargadine JR, Wang AD, Watson A. Central conduction time of somatosensory evoked potentials as a functional monitor in brain ischaemia. In: Proceedings of 10th International Symposium on Cerebral Blood Flow and Metabolism, New York: Raven Press. In press.

${ }^{5}$ Goff GD, Matsumiya Y, Allison T, Goff WR. The scalp topography of human somatosensory and auditory evoked potentials. Electroencephalogr Clin Neurophysiol. 1977;42:57-75.

- Jones SJ. Short latency potentials recorded from the neck and scalp following median nerve stimulation in man. Electroencephalogr Clin Neurophysiol 1977;43:853-63.

' Desmedt JE, O'Cheron GT. Central somatosensory conduction in man: Neural generations and interpeak latencies of the far field components recorded from neck and right or left scalp and earlobes. Electroencephalogr Clin Neurophysiol. 1980;50:382-403.

- Dawson GD. Cerebral responses to nerve stimulation in man. J Neurol Neurosurg Psychiatry 1947;10:134-40.

${ }^{9}$ Matthews WB, Beauchamp M, Small DG. Cervical somatosensory evoked responses in man. Nature, 1974;252:230-232.

${ }^{10}$ Small DG. Peripherally evoked spinal cord potentials in neurological diagnosis. In: Nicholson JP, ed. Scientific aids in Hospital Diagnosis. New York: Plenum Press 1976;155-63.

" El Negamy E, Sedgewick M. Properties of a spinal somatosensory evoked potential in man. $J$ Neurol Neurosurg Psychiatry 1978;41:762-8.

${ }^{12}$ Chiappa KH, Choi SK, Young RR. Short latency. 
Somatosensory evoked potentials following median nerve stimulation in patients with neurological lesions. Clinical uses of cerebral brain stem and spinal somatosensory evoked potentials. Prog Clin Neurophysiol 7. Desmedt JE, ed. Basle: Karger 1980:264-81.

${ }^{13}$ Alison T, Goff WR, Williamson PD. Van Gilder JC. On the neural origin of clinical uses of cerebral, brain stem and spinal somatosensory evoked potentials. Prog Clin Neurophysiol 7, Desmedt JE, ed. Basle: Karger 1980:51-68.

${ }^{14} \mathrm{El}$ Negamy E, Sedgewick M. Delayed somatosensory potentials in cervical spondylosis. J Neurol Neurosurg Psychiatry 1979;42:238-41.
${ }^{15}$ Branston NM, Symon L. Cortical EP, blood flow and potassium changes in experimental ischaemia. In "Evoked potentials". Colin Barker, ed, Manchester MTP. 1980. 527-30.

${ }^{16}$ Symon L. Disordered cerebrovascular physiology in aneurysmal subarachnoid haemorrhage. Acta Neurochir. 41:4-22.

${ }^{17}$ Gilliatt RW, Sears TA. Sensory nerve action potentials in patients with peripheral nerve lesions. $J$ Neurol Neurosurg Psychiatry. 1958;21:109-18.

18 Sklar FH, Ehle AL, Clark WK. Visual evoked potentials: a non-invasive technique to monitor patients with shunted hydrocephalus. Neurosurgery 1979;4:6,529-34. 